Original Research Paper

\title{
Distribution Pattern of SN in Qinghai-Tibet Plateau and Its Relationship with Environmental Factors
}

\author{
${ }^{1}$ Xibo Feng, ${ }^{1}$ Yan He, ${ }^{1}$ Yi Zhang, ${ }^{1}$ Jianlin Wang and ${ }^{2}$ Xiaonan Dong \\ ${ }^{1}$ Xizang Agriculture and Animal Husbandry College, \\ No. 100 YuCai West Road, 860000, Linzhi City, Tibet Autonomous Region, China \\ ${ }^{2}$ School of Art and Design of Wuhan Business University, Wuhan, 430000, China
}

\section{Article history}

Received: $12-03-2020$

Revised: 01-06-2020

Accepted: 01-07-2020

Corresponding Author:

Jianlin Wang

Xizang Agriculture and Animal Husbandry College, No. 100

YuCai West Road,860000,

Linzhi City, Tibet Autonomous Region, China

Email: sunluowang2012@163.com

\begin{abstract}
Studying the distribution pattern and driving mechanism of Soil Nitrogen ( $\mathrm{SN})$ in the agricultural areas of the Qinghai-Tibet Plateau is of certain significance for the rational use of $\mathrm{N}$ fertilizer, improving the quality of land use and protecting the environment. The SN content of cultivated soil in Qinghai-Tibet Plateau agricultural areas was analyzed by combining geographical and meteorological factors. It was found that the average Soil Total N (STN) in farmland was $2.4690 \mathrm{~g} / \mathrm{kg}$, which was the first class standard $(>2.0 \mathrm{~g} / \mathrm{kg})$ of nutrient classification standard in the second national soil census. Horizontally, the areas with low $\mathrm{N}$ are mainly concentrated in the southwest of the Qinghai-Tibet Plateau and the high in the southeast and eastern regions of the Tibetan Plateau. From the vertical distribution pattern of $2000 \mathrm{~m}$ to $5000 \mathrm{~m}$, it gradually decreases with the increase of altitude. The climatic factors affecting the STN are daily average temperature $\geq 10^{\circ} \mathrm{C}$ accumulated temperature > annual evaporation $>$ daily average temperature $\geq 0{ }^{\circ} \mathrm{C}$ accumulated temperature. The climatic factors that affect the Soil Available N (SAN) are daily average temperature $\geq 10^{\circ} \mathrm{C}$ accumulated temperature $>$ daily average temperature $\geq 0^{\circ} \mathrm{C}$ accumulated temperature $>$ annual evaporation> annual sunshine hours $>$ monthly average maximum temperature $>$ annual precipitation amount.
\end{abstract}

Keywords: Qinghai-Tibet Plateau Agricultural Areas, Total N, Available N, Distribution Pattern, Climate Factor

\section{Introduction}

$\mathrm{N}$ is one of the most important nutrients for crop growth (Niu et al., 2010; Liu et al., 2016) and it is also an important limiting element for terrestrial ecosystems (Vitousek and Howarth, 1991). SN is divided into organic $\mathrm{N}$ and inorganic $\mathrm{N}$. SAN refers to the $\mathrm{N}$ that is easily absorbed and used by plants in the soil and mainly includes ammonium $\mathrm{N}$ and nitrate $\mathrm{N}$. Due to the different ecological environments in different regions; the spatial distribution of $\mathrm{SN}$ is also significantly different. SN includes input and output. The input is mainly dry branches and fallen leaves and animal carcasses rarely from the atmosphere and biological $\mathrm{N}$ fixation, however, the output has an effect on the decomposition of organic matter such as temperature, soil moisture and plant characteristics.

Many scholars have conducted in-depth studies on the distribution characteristics of $\mathrm{SN}$ and the driving force behind its formation (Hemu et al., 2018; Mulenga and Siziya, 2019; Nematollahi et al., 2018; Oyola-Guzmán and Oyola-Morales, 2018; Weijden et al., 2019). Someone analyzed the distribution characteristics of SN (including STN and SAN) and the driving forces of climate factors on $\mathrm{SN}$ formation in northeast china (Lv et al., 2010; Wang et al., 2002; Cao et al., 2007). Some scholars believe that climate change will affect vegetation coverage, litter input, soil conditions and affect N dynamics (Moore, 1984). Spatial heterogeneity under climatic conditions will cause drastic changes in soil properties and $\mathrm{N}$ density (Liu et al., 2016; Yang et al., 2007; Xu et al., 2012) will vary greatly with vegetation type and geographical area (LeBauer and Treseder, 2008). Warm and humid climate will increase the mineralization of SN (Liu et al., 2016; Schlesinger and Andrews, 2000) and then affect soil nitrogen storage. The cold and dry climate will reduce $\mathrm{N}$ use efficiency of plants 
and $\mathrm{N}$ mineralization. Climatic factors such as annual average temperature and annual precipitation have significant effects on SN content (Akpa et al., 2016; Nie et al., 2017) studied that the distribution of $\mathrm{N}$ reserves in the northeastern Qinghai-Tibet Plateau indicated that soil $\mathrm{N}$ density decreased from south to north and east to west and the upper 30 and $50 \mathrm{~cm}$ accounted for 42 and $64 \%$ of soil $\mathrm{N}$ respectively (Nie et al., 2017).

In the study of the distribution and formation of SN, scholars have been limited in the study of regional and ecological environmental factors. The study area is relatively small, mainly concentrated in a certain range of forests, grasslands and shrubs. The study on the factors affecting SN content is limited by the unity of the ecological environment and lacks a natural area with large vertical decline of $\mathrm{N}$ spatial distribution of $\mathrm{N}$. The Qinghai-Tibet Plateau is the fourteenth first-class district in China's Modern Agricultural Division (Liu et al., 2018). Agricultural production is dominated by traditional plateau agriculture and animal husbandry. Its unique plateau three-dimensional habitat and plateau climatic conditions provide an ideal field to explore the regional soil $\mathrm{N}$ distribution pattern and related control The $\mathrm{N}$ content of farmland soil is easily disturbed by human factors. Excessive use of $\mathrm{N}$ fertilizer in farmland soil of China has serious acidification problem, which affects the improvement of the yield and quality of agricultural products (Guo et al., 2010). The study on the distribution and driving factors of $\mathrm{N}$ reserves in farmland plays an important role in improving the yield and quality of agricultural products.

This study takes the Qinghai-Tibet Plateau agricultural area as the research area and the spatial distribution of $\mathrm{N}$ content and its influencing factors on a large scale were studied, which is of great significance to the rational use of farmland $\mathrm{N}$ and the increase of production and income in the agricultural area of Qinghai-Tibet Plateau.

\section{Materials and Methods}

\section{Overview of the Study Area and Layout of the Sample Points}

The research area involves the main agricultural planting areas in Sichuan, Gansu, Qinghai and Tibet. It passes through 7 natural vegetation zones, including mountain steppe, alpine meadow steppe, alpine shrub meadow, mountain coniferous forest, mountain shrub steppe, mountain desert and semi-desert. The annual average sunshine hours are $1642-3393 \mathrm{~h}$; the annual average temperature $-0.6-12.9^{\circ} \mathrm{C}$ and the annual average precipitation is $150-890 \mathrm{~mm}$. According to the distribution pattern of atmospheric temperature and precipitation on the Qinghai-Tibet Plateau, 71 typical samples were set in different ecological planting areas $\left(\left(27-38^{\circ} \mathrm{N}, 79-104^{\circ} \mathrm{E}\right)\right.$. The sampling points are shown in Fig. 1.

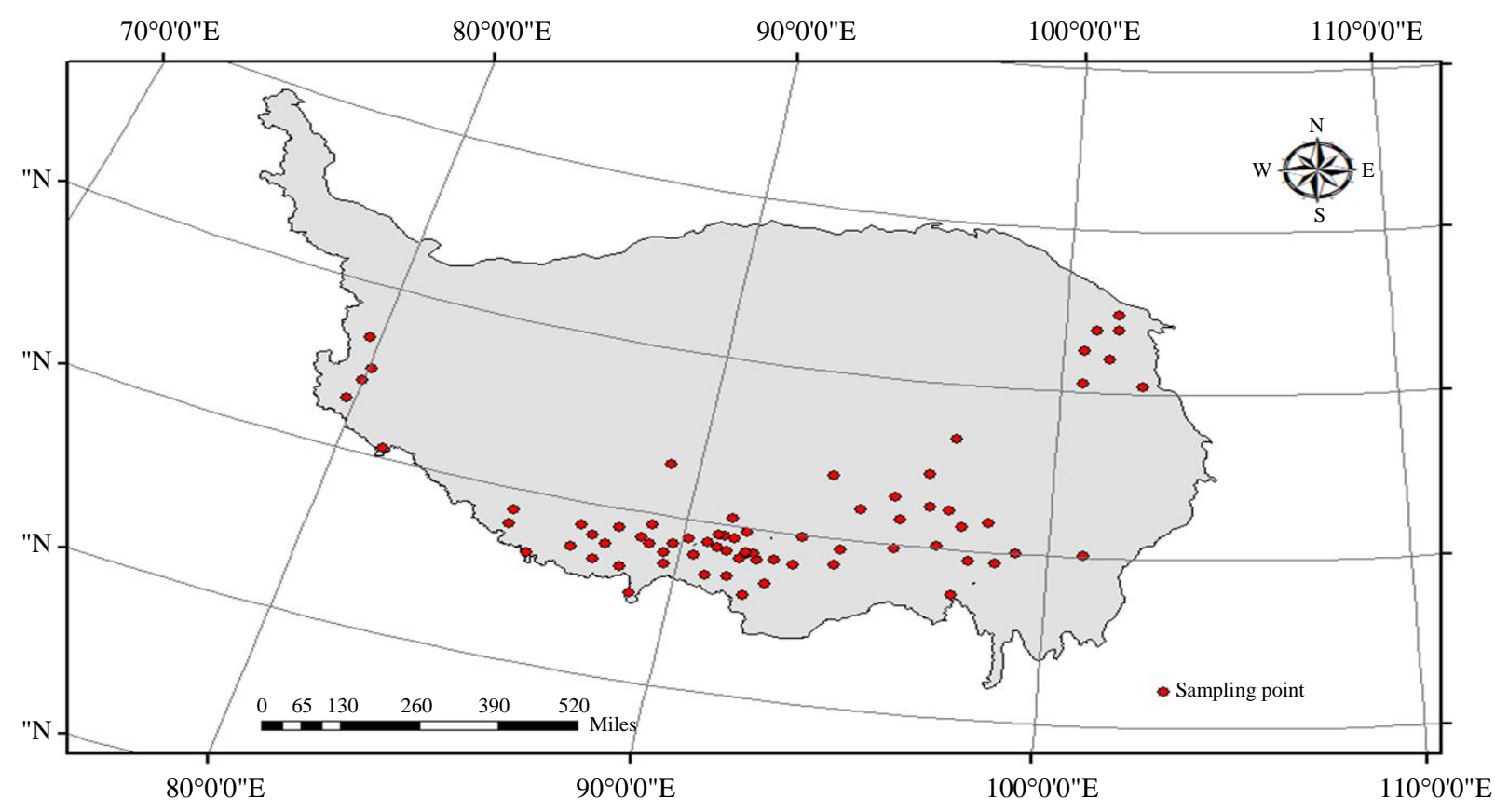

Fig. 1: Distribution of sampling point 


\section{Collection and Analysis of Soil Samples}

Soil samples were collected at various sites in October 2018 and October 2019 after the crops were harvested for two consecutive years. According to the requirements of the People's Republic of China on the Guidelines for Soil Quality and Soil Sampling Technology (GB/T 36197, 2018), each sample point is selected into a piece of farmland about 10 ha. Before sampling, GPS is used to locate each sample point and then S-shape is set for 20 mining points. The soil samples of the tillage layer $(0-30 \mathrm{~cm})$ were collected and the soil samples were packed into soil bags and mixed. Each sample was mixed with about $1 \mathrm{~kg}$ of soil samples. After returning to the laboratory for air drying, the soil samples were manually selected to remove fine roots and then grind it with $1 \mathrm{~mm}$ sieve to determine the STN and SAN. STN and available $\mathrm{N}$ are measured by the semi-micro Kjeldahl method (using an instrument of Shanghai ATN-500 automatic Kjeldahl meter) (Cheng, 2016). The STN and SAN are two-year averages.

\section{Climatological Information}

The climatic data of each sample point was from the National Meteorological Science Data Center http://data.cma.cn/ and the climate factor is an average of 30 years.

\section{Statistical Analysis}

First, the STN and SAN of 71 samples were divided into 5 categories and then the spatial distribution map was made with ARCGIS 10.3 software and SPASS 25 was used for statistical analysis. The least significant difference method was used to compare the differences between the data groups $(\alpha=0.05)$ and the relationship between geographic factors, climatic factors and $\mathrm{N}$ content was estimated by ordinary least squares regression.

\section{Results and Analysis}

It can be seen from Table 1 that the average STN content of farmland in the Qinghai-Tibet Plateau is $2.4690 \mathrm{~g} / \mathrm{kg}$, which belongs to the first-level standard $(>2.0 \mathrm{~g} / \mathrm{kg}$ ) of the nutrient classification standard for the second national soil census. The maximum value is 8 $\mathrm{g} / \mathrm{kg}$ and the minimum value of $0.7 \mathrm{~g} / \mathrm{kg}$ belongs to the five-level standard $(0.5-0.75 \mathrm{~g} / \mathrm{kg})$. The $\mathrm{N}$ content varies greatly at different points. The variability of SAN is greater than that of STN.

Table 1: Comparison of STN and SAN

\begin{tabular}{lll}
\hline & STN g/kg & SAN g/kg \\
\hline Max. & 8.0000 & 0.7635 \\
Min. & 0.7000 & 0.0054 \\
Range & 7.3000 & 0.7096 \\
Mean & 2.4690 & 0.2191 \\
Std. Deviation & 1.2866 & 0.1426 \\
CV & 0.5211 & 0.6509 \\
\hline
\end{tabular}

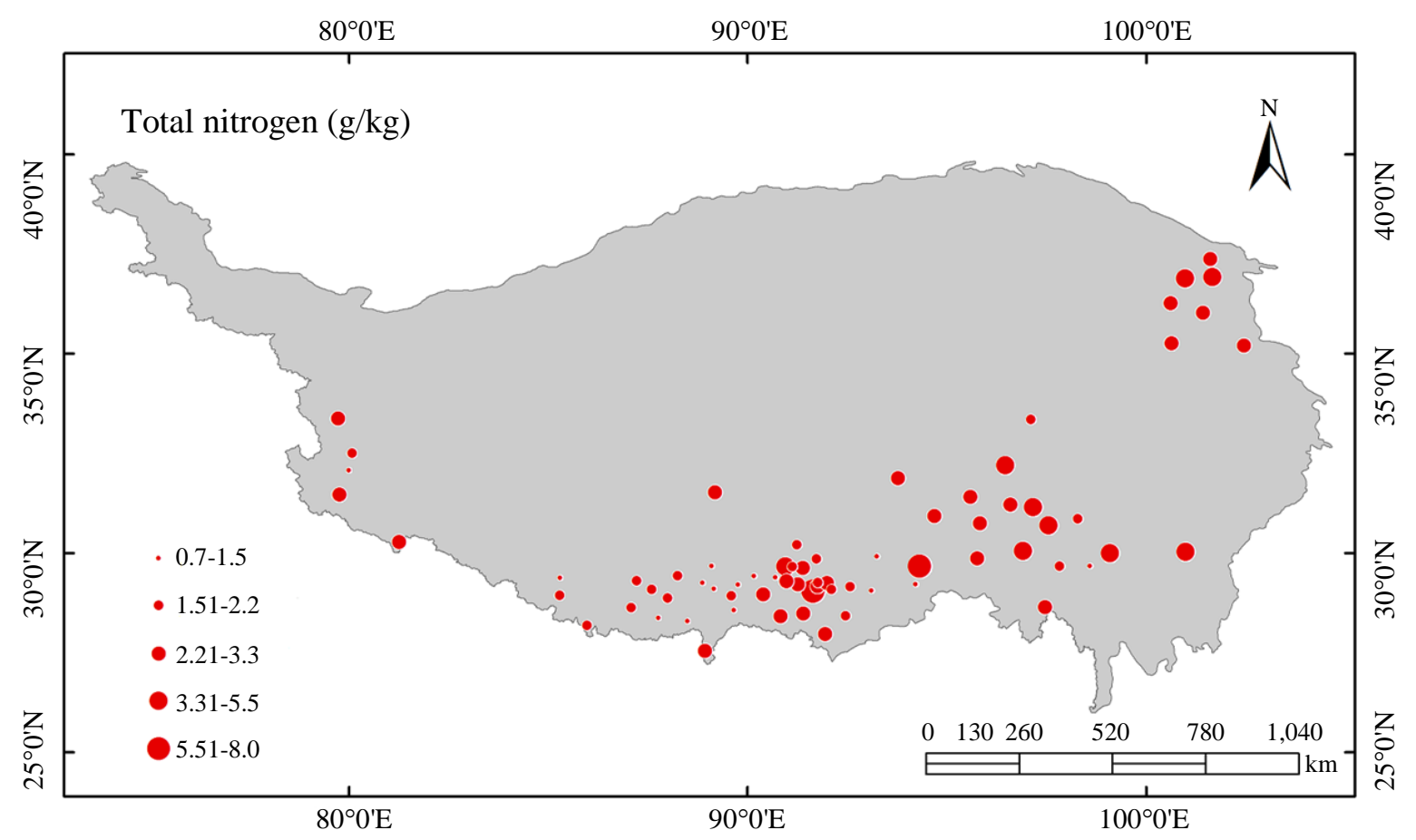

Fig. 2: Distribution of STN 


\section{Horizontal Distribution Pattern of SN Content}

It can be seen from Figures 2 that areas with low STN (STN <1.5 g/kg, which belongs to the second national soil census nutrient classification standard below the third level) are mainly concentrated in the southwest of the Qinghai-Tibet plateau, including Gar County, Gangba County and Saga County of Tibet Autonomous Region; High-value areas (STN> $1.5 \mathrm{~g} / \mathrm{kg}$, which is the second national soil census nutrient grading standard of Grade II or higher) are mainly concentrated in the southeast and eastern areas of the Qinghai-Tibet Plateau. It mainly includes Sangri County, Zhalang County, Longzi County, Chayu County of Tibet Autonomous Region, Haiyan City and Datong County of Qinghai Province and Batang County of Sichuan Province. In order to further analyze the effect of horizontal geographic factors on latitude and longitude of $\mathrm{SN}$, regression analysis was performed by taking latitude $\left(X_{1}\right)$ longitude $\left(X_{2}\right)$ as the independent variable and $\mathrm{SN}\left(\mathrm{STN} Y_{1}, \mathrm{SAN} Y_{2}\right)$ as the dependent variable. The regression equation is as follows:

$$
\begin{aligned}
& Y_{1}=0.1063 X_{1}+0.3199 X_{2} \\
& \left(R=0.3812 * *, R_{1}=0.1013, R_{2}=0.2929 *\right) \\
& Y_{2}=0.2098 X_{1}+0.3022 X_{2} \\
& \left(R=0.4409 * *, R_{1}=0.2027, R_{2}=0.2857 *\right)
\end{aligned}
$$

*means the difference is significant at the 0.01 level $(P<0.05)$; **means the difference is significant at the 0.01 level $(P<0.01)$

The two regression equations passed test at the level of $\alpha=0.01$. Latitude and longitude had a significant effect on $\mathrm{SN}$. The SN content increased with the increase of latitude and longitude and the longitude effect was greater than the latitude. Partial correlation analysis showed that longitude had a significant effect on $\mathrm{SN}$ content.

\section{Vertical Distribution Characteristics of Soil Nitrogen Content}

Figure 3 and 4 which show a correlation between altitude and SN of soil samples. The regression analysis was carried out taking altitude as independent variable $(X)$ and SN content as dependent variable $(Y)$. The regression equation passed an extremely significant test at the level of $\alpha=0.01$, which can explain the relationship between altitude and SN.SN decreases with the increase of altitude and the effect of altitude on the SAN is greater than that on the STN.

\section{Relationship between SN Content and Climate Factors in the Tibetan Plateau}

Based on stepwise regression analysis, taking the SN content as the dependent variable (STN $\left(Y_{1}\right)$, SAN $\left.\left(Y_{2}\right)\right)$, the monthly average temperature $\left(X_{1}\right)$, the monthly average relative humidity $\left(X_{2}\right)$ and the monthly average minimum temperature $\left(X_{3}\right)$, monthly average maximum temperature $\left(X_{4}\right)$, annual sunshine hours $\left(X_{5}\right)$, annual precipitation $\left(X_{6}\right)$, annual evaporation $\left(X_{7}\right)$, daily average temperature $\geq 0{ }^{\circ} \mathrm{C}$ accumulated temperature $\left(X_{8}\right)$ and daily average temperature $\geq 10^{\circ} \mathrm{C}$ accumulated temperature $\left(X_{9}\right)$ is the independent variable. The optimal regression equation is established and the significance test is carried out at the level of $\alpha=0.05$ :

$$
\begin{aligned}
& Y_{1}=-0.3028 X_{7}-0.2599 X_{8}+0.4516 X_{9} \\
& \left(R=0.3401^{*}, R_{7}=-0.0223^{*}, R_{8}=-0.1335, R_{9}=0.2316\right) \\
& Y_{2}=-0.1081 X_{4}-0.1618 X_{5}+0.08020 X_{6} \\
& -0.2163 X_{7}-0.3373 X_{8}+0.5701 X_{9} \\
& \left(\begin{array}{l}
R=0.4303^{*}, R_{4}=-0.0860, R_{5}=-0.1029, R_{6} \\
=0.0668, R_{7}=-0.1616, R_{8}=-0.1721, R_{9}=0.2724^{*}
\end{array}\right)
\end{aligned}
$$

"means the difference is significant at the 0.01 level

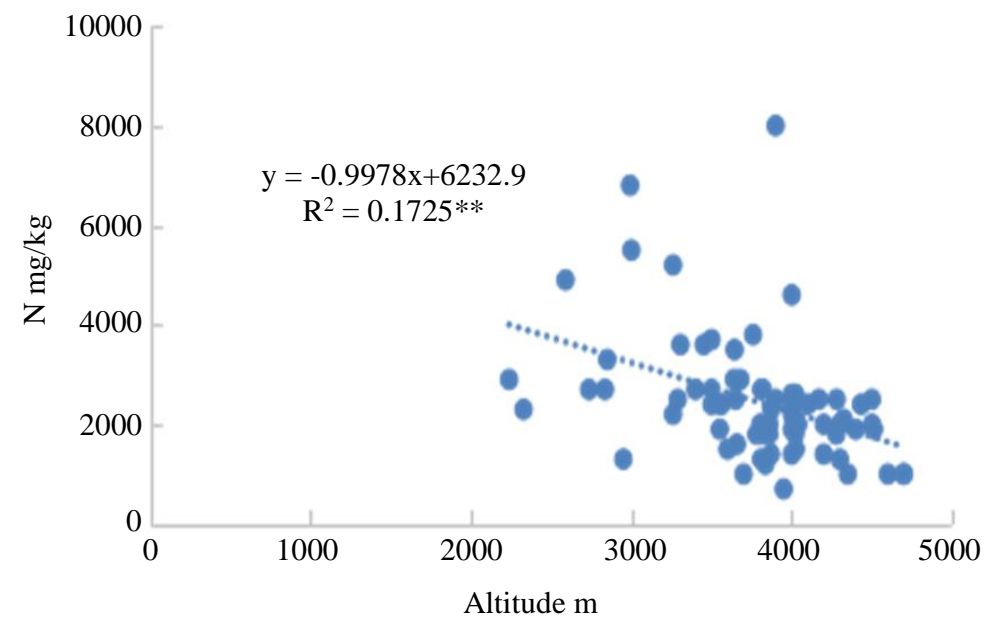

Fig. 3: Relationship between altitude and soil total $\mathrm{N}$ 


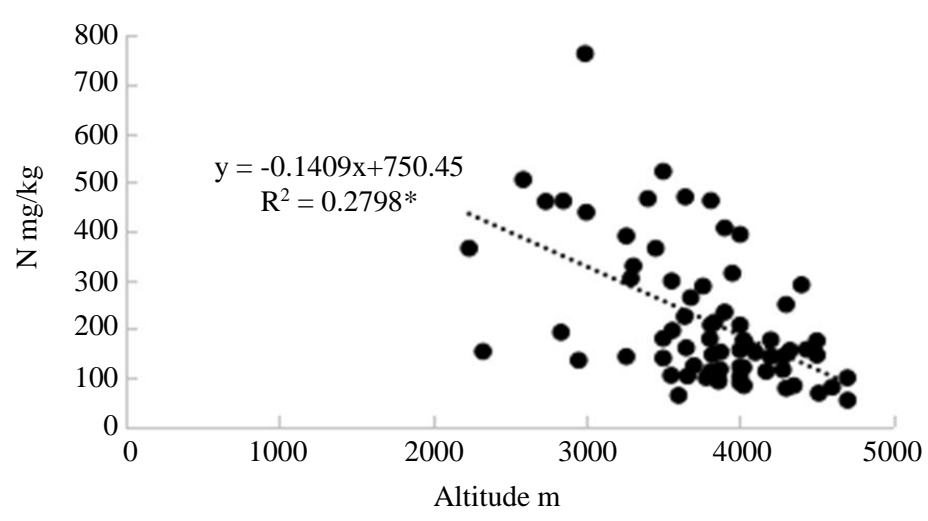

Fig. 4: Relationship between altitude and available N; **means the difference is significant at the 0.01 level

Table 2: Path analysis of STA and climatic factors in farmland of the Qinghai-Tibet Plateau

\begin{tabular}{lllll}
\hline Variables & Direct coefficient & $\rightarrow X_{7}$ & $\rightarrow X_{8}$ & $\rightarrow X_{9}$ \\
\hline$X_{7}$ & -0.3028 & & 0.0511 & 0.0347 \\
$X_{8}$ & -0.2599 & 0.0595 & & 0.3763 \\
$X_{9}$ & 0.4516 & -0.0233 & -0.2165 & \\
Residual Path Coefficient & 0.9404 & & & \\
\hline
\end{tabular}

Table 3: Path analysis of available $N$ content and climatic factors in farmland of the Qinghai-Tibet Plateau

\begin{tabular}{lcrrrrrr}
\hline Variables & Direct coefficient & $\rightarrow X_{4}$ & $\rightarrow X_{5}$ & $\rightarrow X_{6}$ & \multicolumn{1}{c}{$\rightarrow X_{7}$} & $\rightarrow X_{8}$ & $\rightarrow X_{9}$ \\
\hline$X_{4}$ & -0.1081 & & 0.0488 & 0.0197 & -0.0048 & -0.1991 & 0.3908 \\
$X_{5}$ & -0.1618 & 0.0326 & & -0.0514 & -0.1392 & 0.1771 & -0.1891 \\
$X_{6}$ & 0.0802 & -0.0266 & 0.1037 & & 0.0884 & -0.1401 & 0.1332 \\
$X_{7}$ & -0.2163 & -0.0024 & -0.1041 & -0.0328 & & 0.0663 & 0.0438 \\
$X_{8}$ & -0.3373 & -0.0638 & 0.0850 & 0.0333 & 0.0425 & & 0.4749 \\
$X_{9}$ & 0.5701 & -0.0741 & 0.0537 & 0.0187 & -0.0166 & -0.2810 & \\
Residual path coefficient & 0.9027 & & & & & & \\
\hline
\end{tabular}

It can be seen from the equation that the climatic factors affecting the $\operatorname{STN}\left(Y_{1}\right)$ are annual evaporation $\left(X_{7}\right)$, daily average temperature $\geq 0{ }^{\circ} \mathrm{C}$ accumulated temperature $\left(X_{8}\right)$ and average daily temperature $\geq 10^{\circ} \mathrm{C}$ accumulated temperature $\left(X_{9}\right)$. Monthly average temperature $\left(X_{1}\right)$, monthly average relative humidity $\left(X_{2}\right)$, monthly average minimum temperature $\left(X_{3}\right)$, monthly average maximum temperature $\left(X_{4}\right)$, monthly hours of sunshine $\left(X_{5}\right)$, the annual precipitation $\left(X_{6}\right)$ has little effect on the STN. The climatic factors that affect the SAN $\left(Y_{2}\right)$ are the monthly average maximum temperature $\left(X_{4}\right)$, the annual sunshine hours $\left(X_{5}\right)$, the annual precipitation $\left(X_{6}\right)$ and the annual evaporation $\left(X_{7}\right)$, Daily average temperature $\geq 0{ }^{\circ} \mathrm{C}$ accumulated temperature $\left(X_{8}\right)$, Daily average temperature $\geq 10^{\circ} \mathrm{C}$ accumulated temperature $\left(X_{9}\right)$. The monthly average temperature $\left(X_{1}\right)$, the monthly average relative humidity $\left(X_{2}\right)$ and the monthly average minimum temperature $\left(X_{3}\right)$ have little effect on the SAN. Partial regression analysis found that the annual evaporation $\left(X_{7}\right)$ had a significant effect on the STN and the effect was negative. The daily average temperature $\geq 10^{\circ} \mathrm{C}$ accumulated temperature $\left(X_{9}\right)$ has a significant positive effect on the content of the SAN.

It can be seen from Table 2 that the order of the climatic factors directly affect the STN is the daily average temperature $\geq 10^{\circ} \mathrm{C}$ accumulated temperature $\left(X_{9}\right)>$ annual evaporation $\left(X_{7}\right)>$ daily average temperature $\geq 0{ }^{\circ} \mathrm{C}$ accumulated temperature $\left(X_{8}\right)$. Among them, $X_{9}$ is a positive contribution and $X_{7}$ and $X_{8}$ are negative direct contributions. The daily average temperature $\geq 0^{\circ} \mathrm{C}$ accumulated temperature $\left(X_{8}\right)$ has a small direct contribution to the SAN, while the daily average temperature $\geq 10^{\circ} \mathrm{C}$ accumulated temperature has a large direct contribution.

It can be seen from Table 3 that the direct contribution of climatic factors to the SAN is $X_{9}>X_{8}>X_{7}$ $>X_{5}>X_{4}>X_{6}$. Except positive contributions $X_{9}$ and $X_{6}$, all other factors are negative contributions. The monthly average maximum temperature $\left(X_{4}\right)$ has a small direct contribution to the SAN and indirect contribution through $\geq 10^{\circ} \mathrm{C}$ accumulated temperature $\left(X_{9}\right)$.

\section{Discussion}

This study indicates that the average the STN on the Qinghai-Tibet Plateau is $2.4690 \mathrm{~g} / \mathrm{kg}$, which is a firstclass standard (> $2.0 \mathrm{~g} / \mathrm{kg}$ ) for the second national soil census nutrient classification standard. This shows that the $\mathrm{N}$ input in the farmland ecosystem of the Tibetan 
Plateau is much larger than the output. For farmland ecosystems, the input channels of $\mathrm{N}$ mainly include chemical $\mathrm{N}$ and organic fertilizers applied, biological $\mathrm{N}$ fixation, wet and dry deposition of the atmosphere and irrigation water. The output channels include $\mathrm{N}$ removed with the harvest and denitrification (Zhou and Shen, 2013). Over the past 30 years, In China, excessive application of $\mathrm{N}$ is common in farmland (Zhang et al., 2009) and that in the Qinghai-Tibet Plateau is no exception. This is one of the important reasons for the high $\mathrm{N}$ content in the farmland of the Qinghai-Tibet Plateau. In addition, the increase of $\mathrm{N}$ deposition in the Tibetan Plateau will also increase the SN content (Liu et al., 2015). In addition, the Qinghai-Tibet Plateau agriculture is more focused on the combination of agriculture and animal husbandry. Tibetans feed their livestock with crop straws and their manure is sent back to farmland to reduce nitrogen output.

This study shows that in the horizontal distribution pattern of SN in the farmland in the Qinghai-Tibet Plateau, areas with low $\mathrm{N}$ content are mainly concentrated in the southwest of the Qinghai-Tibet Plateau and the high-value areas are mainly concentrated in the southeast and east of the Qinghai-Tibet Plateau. The general trend increases with the increase of latitude and longitude, but the effect of longitude is obviously greater than that of latitude. The Qinghai-Tibet Plateau is high in the northwest and low in the southeast. The low southeast is the alpine canyon extending from north to south. Its agricultural areas are mainly in the Yarlung Zangbo Valley and Huangshui Valley in the southeast. From northwest to Southeast, the longitude of Qinghai Tibet Plateau changes greatly and the water and heat resources change obviously, which have a significant impact on crop planting systems and soil conditions and then affect the distribution pattern of $\mathrm{N}$.

This study indicates that the vertical distribution pattern of SN in the farmland of the Tibetan Plateau is from 2000 to $5000 \mathrm{~m}$ and gradually decreases with the increase of altitude. Some scholars think so (Nie et al., 2017). Different altitudes result in different warm and hot precipitation. The lowest elevation of the agricultural areas on the Tibetan Plateau is $<1000 \mathrm{~m}$ and the highest elevation is $4750 \mathrm{~m}$ (Gangba County, Tibet Autonomous Region). Its three-dimensional features are rare in the world. The change from humid to semi-humid on the Qinghai-Tibet Plateau and from drought to semi-arid is significantly correlated with altitude. The SAN is easily absorbed by plants and temperature and moisture have great effect on $\mathrm{N}$ mineralization (Björsne et al., 2014). The main reasons for the influence of altitude on the SAN content are elevation rise and fall, large changes in temperature and hot water, different crop planting systems, different soil types and different soil microbial activity.
This study indicates that the climatic factors affecting the STN content are daily average air temperature $\geq 10^{\circ} \mathrm{C}$ accumulated temperature > annual evaporation> daily average air temperature $\geq 00^{\circ} \mathrm{C}$ accumulated temperature and SAN content are daily average temperature $\geq 10^{\circ} \mathrm{C}$ accumulated temperature $>$ daily average temperature $\geq 0^{\circ} \mathrm{C}$ accumulated temperature $>$ annual evaporation > annual sunshine hours > monthly average maximum temperature $>$ annual precipitation amount. Some scholars believe that there is a significant positive correlation between $\mathrm{N}$ storage and annual average temperature and precipitation (Nie et al., 2017; Wang et al., 2003). Some scholars believe that $\mathrm{SN}$ content is positively related to annual average temperature and negatively correlated with precipitation (Wang et al., 2003). The reasons are due to different types of vegetation, vegetation coverage, soil types and planting systems. Qinghai-Tibet Plateau is a typical area with low-latitude and high-altitude, with generally less precipitation, longer sunshine hours and larger evaporation. Qinghai Tibet Plateau is a typical area with low latitude and high altitude, with less precipitation, longer sunshine hours and larger evaporation. Compared with precipitation, evaporation has become an important limiting factor of SN content due to the special environment of the Qinghai-Tibet Plateau. Everyone agrees that the average annual temperature has a significant effect on SN and this study supports this view. However, it is believed that the daily average temperature $\geq 10^{\circ} \mathrm{C}$ accumulated temperature has a great impact on SN content. The reason is that the annual temperature in the agricultural areas of the Qinghai-Tibet Plateau is relatively low and the accumulated temperature, especially $\geq 10^{\circ} \mathrm{C}$, is an effective temperature for crop growth and development. Crop growth is vigorous, SAN absorption is stronger, rhizosphere microorganism is more active, $\mathrm{SN}$ content will change greatly. Although there is a significant positive correlation between SAN content and STN content, there are certain differences in influencing factors. The annual sunshine hours, the monthly average maximum temperature and the annual precipitation have a certain effect on the SAN content. The SAN is mainly ammonium and nitrate, which is easily absorbed by crops and its content is closely related to the growth period of crops. Barley is the main crop in Qinghai Tibet Plateau, with short growth period from March to September every year. The annual sunshine hours, monthly average maximum temperature and annual precipitation have significant effects on the growth and development of barley and have obvious seasonality, which is basically consistent with the growth and development cycle of barley. These three factors have a significant effect on the SAN content and are related to the main crops grown on the Tibetan Plateau.

The mathematical model of N content $R^{2}$ in this study is small and the remaining path coefficient is large, 
which fully shows that the factors affecting SN content are more complicated and each factor does not fully explain the SN content. SN content and its driving factors need to be further studied and tested.

\section{Conclusion}

The average STN in farmland on the Qinghai-Tibet Plateau is $2.4690 \mathrm{~g} / \mathrm{kg}$, which is a first-class standard (> $2.0 \mathrm{~g} / \mathrm{kg}$ ) for the second national soil census nutrient classification standard. Low $\mathrm{N}$ are mainly concentrated in the southwest and the high are mainly concentrated in the southeast and east of the Qinghai-Tibet Plateau in the horizontal direction. The SN content gradually decreases with the increase of altitude from 2000 to $5000 \mathrm{~m}$ and altitude affects SAN more than STN. The climatic factors affecting STN are daily average air temperature $\geq 10^{\circ} \mathrm{C}$ accumulated temperature $>$ annual evaporation $>$ daily average air temperature $\geq 0{ }^{\circ} \mathrm{C}$ accumulated temperature and affecting $\mathrm{SAN}$ are daily average temperature $\geq 10^{\circ} \mathrm{C}$ accumulated temperature $>$ daily average temperature $\geq 0^{\circ} \mathrm{C}$ accumulated temperature > annual evaporation > annual sunshine hours > monthly average maximum temperature $>$ annual precipitation amount. In the context of global climate warming, this study provides a scientific basis for the distribution and formation mechanism of $\mathrm{N}$ in the farmland soil on the third pole of the earth-the Tibetan Plateau, which is of great significance to the rational use of nitrogen and to promote the increase of production and income of farmers and herdsmen.

\section{Acknowledgment}

We thank Zihao Wang for drawing the paper. This study was funded by The Central Government supported the development and reform project of Tibetan local colleges and universities (project number: 503118001) and the central government led the local project (YDZX20195400004717).

\section{Author's Contributions}

Xibo Feng: Conceived and designed the experiments and wrote the paper.

Yan He: Conceived and designed the experiments.

Yi Zhang and Xiaonan Dong: Analyzed the data.

Jianlin Wang: Contributed reagents/materials/ analysis tools.

All authors read and approved the final manuscript.

\section{Ethics}

The authors declare their responsibility for any ethical issues that may arise after the publication of this manuscript.

\section{Conflict of Interest}

The authors declare that they have no competing interests. The corresponding author affirms that all of the authors have read and approved the manuscript.

\section{References}

Akpa, S.I.C., I.O.A. Odeh, T.F.A. Bishop, A.E. Hartemink and I.Y. Amapu, 2016. Total soil organic carbon and carbon sequestration potential in Nigeria.Geoderma, 271: 202-215.

DOI: 10.1016/j.geoderma.2016.02.021

Björsne, A.K., T. Rütting and P. Ambus, 2014. Combined climate factors alleviate changes in gross soil nitrogen dynamics in heathlands. Biogeochemistry, 120: 191-201. DOI: $10.1007 / \mathrm{s} 10533-014-9990-1$

Cheng, Q., 2016. Method for determining soil total nitrogen content by Kjeldahl nitrogen on the Tibetan plateau. Tibet J. Agric. Sci., 38: 28-31.

Cao, H.J., J. Wang, S.Y. Li and J.J. Zou, 2007. Effect of graduients of precipitation and temperature and fertilization on organic carbon and nitrogen of soils in Northeastern China. J. Soil Water Conserv., 21: 122-125

GB/T 36197, 2018. Soil quality a guide to soil sampling techniques. China

Guo, J.H., X.J. Liu, Y. Zhang, J.L. Shen and W.X. Han et al., 2010. Significant acidification in major Chinese croplands. Science, 327: 1008-1010. DOI: $10.1126 /$ science. 1182570

Hemu, A. Kumar, A. Raja and A. Murtaza, 2018. Correlation between chemical and index properties of soils of Hyderabad region. Civil Eng. J., 4: 2821-2821. DOI: 10.28991/cej-03091201

LeBauer, D.S. and K.K. Treseder, 2008. Nitrogen limitation of net primary productivity in terrestrial ecosystems is globally distributed. Ecology, 89: 371-379. DOI: 10.1890/06-2057.1

Liu, Y.S., Z.W. Zhang and J.Y. Wang, 2018. Regional differentiation and comprehensive regionalization scheme of modern agriculture in China. Acta Geographica Sinica, 73: 203-218.

Liu, Y.W., Y.S. Wang, Y.P. Pan and S.L. Wang, 2015. Wet deposition of atmospheric inorganic nitrogen at five remote sites in the Tibetan Plateau. Atmos. Chem. Phys., 15: 11683-11700.

DOI: $10.5194 /$ acp-15-11683-2015

Liu, Y., C. Wang, N. He, X. Wen and Y. Gao et al., 2016. A global synthesis of the rate and temperature sensitivity of soil nitrogen mineralization: Latitudinal patterns and mechanisms. Global Change Biol., 23: 455-464.

DOI: $10.1111 /$ gcb.13372 
Lv, G.H., X.Y. Wang, Y.S. Zhang, Q.Y. Jia and Y.B Xie, 2010. Soil carbon, nitrogen of the farmland and their relationships with climatic factors. J. Agro-Environ. Sci., 29: 1612-1617.

Moore, T.R., 1984. Litter decomposition in a sub-arctic, spruce-lichen woodland in eastern Canada. Ecology, 65: 199-308. DOI: 10.2307/1939482

Mulenga, D. and S. Siziya, 2019. Indoor air pollution related respiratory ill health, a sequel of biomass use. SciMedicine J., 1: 30-37. DOI: $10.28991 /$ SciMedJ-2019-0101-5

Nematollahi, H., N. Moradi, M. Riyazinejad and H. Vahidi, 2018. Removal of aliphatic hydrocarbons from gas oil contaminated clay soil via soil vapor extraction. Civil Eng. J., 4: 1858-1868.

DOI: 10.28991/cej-03091120

Nie, X.Q., F. Xiong, L. Yang, C. Li and G. Zhou, 2017. Soil storage, distribution and associated controlling factors in the northeast Tibetan plateau shrublands. Forests, 8: 416-416. DOI: 10.3390/f8110416

Niu, S., M. Wu, Y.I. Han, J. Xia and Z.H.E. Zhang et al., 2010. Nitrogen effects on net ecosystem carbon exchange in a temperate steppe. Glob. Chang. Biol., 16: 144-155. DOI: 10.1111/j.1365-2486.2009.01894.x

Oyola-Guzmán, R.D. and R. Oyola-Morales, 2018. Forensic evaluation of compacted soils using ramcodes. Civil Eng. J., 4: 2275-2283. DOI: $10.28991 /$ cej-03091157

Schlesinger, W.H. and J.A. Andrews, 2000. Soil respiration and the global carbon cycle. Biogeochemistry, 48: 7-20. DOI: 10.1023/a:1006247623877

Vitousek, P.M. and R.W. Howarth, 1991. Nitrogen limitation on land and in the sea: How can it occur? Biogeochemistry, 13: 87-115. DOI: $10.2307 / 1468901$
Weijden, V.A.V.D., A.K. Hankele, A.B. Rüegg, M. Schmicke and S.E. Ulbrich, 2019. Progestogen profiling over the course of diapause and resumption of embryo development in the European roe deer. SciMedicine J., 1: 158-167.

DOI: 10.28991/SciMedJ-2019-0104-1

Wang, S.P., G.S. Zhou and Y.C. Lv, 2003. Distribution of soil carbon, nitrogen and phosphorus along Northeast China Transect and their relationships with climatic factors. Chinese J. Plant Ecol., 26: 513-517.

Wang, S.P., G.S. Zhou Y.C. Lu and J.J. Zou, 2002. Distribution of soil carbon, nitrogen and phosphorus along Northeast China Transect (NECT) and their relationships with climatic factors. Acta Phytoecol. Sinica, 26: 513-517.

Xu, X., P.E. Thornton and W.M. Post, 2012. A global analysis of soil microbial biomass carbon, nitrogen and phosphorus in terrestrial ecosystems. Global Ecol. Biogeography, 22: 737-749.

DOI: $10.1111 /$ geb.12029

Yang, Y.H., W.H. Ma, A. Mohammat and J.Y. Fang, 2007. Storage, patterns and controls of soil nitrogen in China. Pedosphere, 17: 776-785. DOI: $10.1016 / \mathrm{s} 1002-0160(07) 60093-9$

Zhang, P., T. Zhang and N.L. Chen, 2009. Vertical distribution patterns of soil organic carbon and total nitrogen and related affecting factors along northern slope of Qilian Mountains. Chinese J. Applied Ecol., 20: 518-524. DOI: 10.13287/j.1001-9332.2009.0105

Zhou, J.M. and R.F. Shen, 2013. Dictionary of Soil Science. 1st Edn., Science Press, Beijing, China. 